\title{
The Biosocial Approach to Human Development, Behavior, and Health Across the Life Course
}

\author{
KATHLEEN MULLAN HARRIS AND THOMAS W. MCDADE
}

Social, cultural, economic, and biological factors are widely recognized as critical determinants of well-being across the life course. Yet an integrative understanding of the multilevel biosocial pathways linking society, biology, health, and socioeconomic attainment remains elusive. The objective of this issue is to showcase research that integrates theory, data, and methods from the social and biological sciences to advance our understanding of social and biological processes that contribute to, or derive from, social stratification across the life course. In this introduction, we describe the state of current research and discuss both the motivation for and relevant concepts underlying a biosocial perspective. We review the themes and research contributions in this issue, and chart a course forward for understanding biosocial pathways of well-being across the life course.

\section{BRINGING TOGETHER THE}

BIOLOGICAL AND THE SOCIAL

The term biosocial is widely used in the social sciences, but rarely defined. Perhaps its meaning is self-evident. And though the term has appeared in the scientific literature for more than fifty years, approaches and applications in biosocial research have shifted qualitatively over the past fifteen years. ${ }^{1}$ In this section, we discuss these developments and the synergies afforded by integrating perspectives from the social and biological sciences.

We define biosocial as a broad concept referencing the dynamic, bidirectional interactions between biological phenomena and social relationships and contexts, which constitute processes of human development over the life course. It is difficult, if not impossible, to represent the complexities of these biosocial dynamics in two dimensions, but we attempt to

Kathleen Mullan Harris is James E. Haar Distinguished Professor of Sociology and faculty fellow of the Carolina Population Center at the University of North Carolina at Chapel Hill. She is also a member of the National Academy of Sciences and director of the National Longitudinal Study of Adolescent to Adult Health (Add Health). Thomas W. McDade is Carlos Montezuma Professor of Anthropology and faculty fellow of the Institute for Policy Research at Northwestern University. He is also a senior fellow in the Child and Brain Development Program of the Canadian Institute for Advanced Research.

(C) 2018 Russell Sage Foundation. Harris, Kathleen Mullan, and Thomas W. McDade. 2018. “The Biosocial Approach to Human Development, Behavior, and Health Across the Life Course." RSF: The Russell Sage Foundation Journal of the Social Sciences 4(4): 2-26. DOI: 10.7758/RSF.2018.4.4.01. Direct correspondence to: Kathleen Mullan Harris at kathie_harris@unc.edu, University of North Carolina, 206 W. Franklin St., Chapel Hill, NC 27516; and Thomas W. McDade at t-mcdade@northwestern.edu, Northwestern University, 1810 Hinman Ave., Evanston, IL 60208.

Open Access Policy: RSF: The Russell Sage Foundation Journal of the Social Sciences is an open access journal. This article is published under a Creative Commons Attribution-NonCommercial-NoDerivs 3.0 Unported License.

1. In 1969, both the Journal of Biosocial Science and Social Biology began publishing. In 2008, Social Biology was renamed to Biodemography and Social Biology, the journal of the Society for Biodemography and Social Biology. 
Figure 1. Conceptual Model of Biosocial Dynamics Across the Life Course

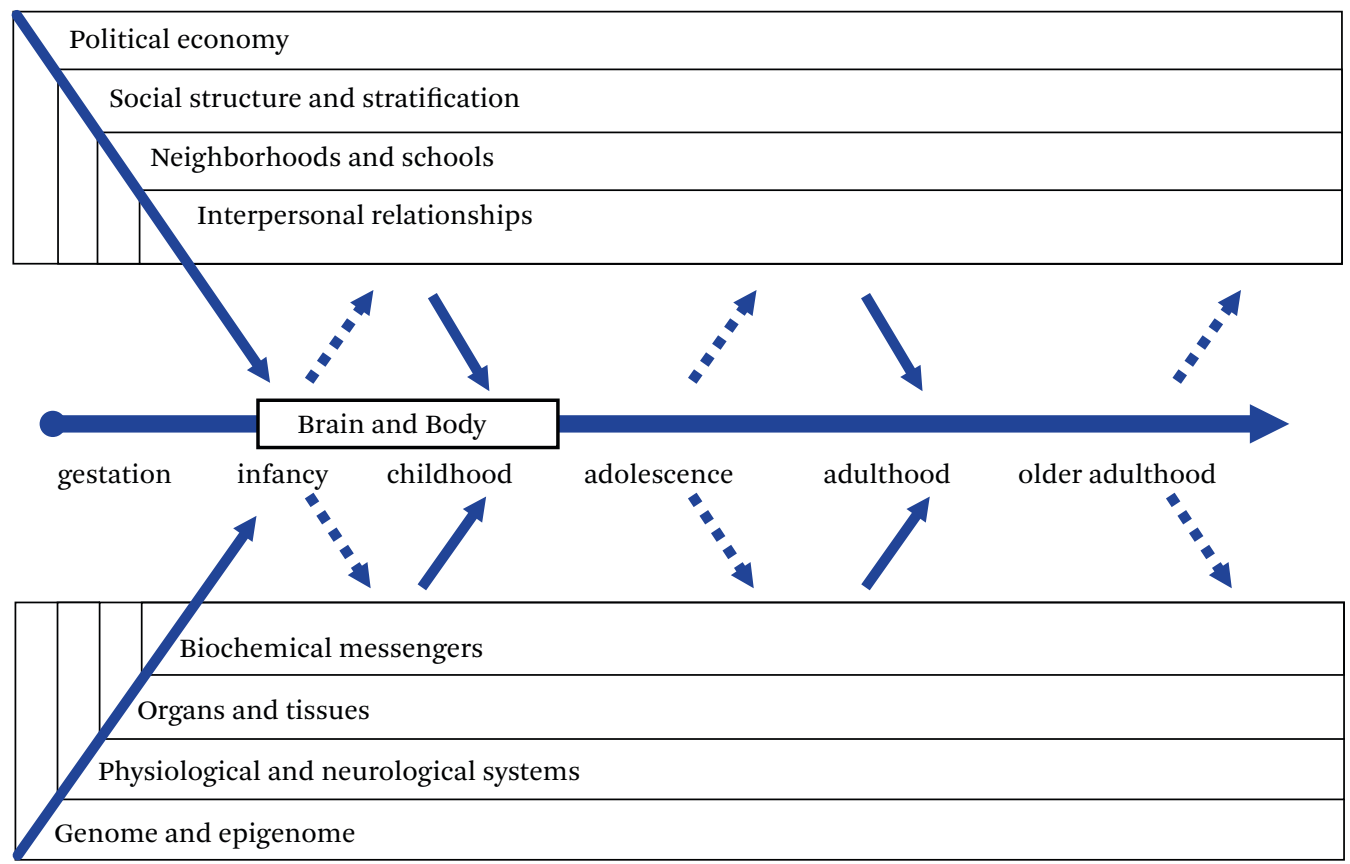

Source: Authors' compilation.

do so in figure 1 , which builds on prior efforts to highlight the multilevel domains and pathways of particular importance in biosocial approaches to health and social inequality (Kuh and Ben-Shlomo 2004; Glass and McAtee 2006). The top boxes represent the set of nested and interacting social contexts "outside" the body that affect the developing brain and body of an individual throughout all stages of the life course. Similarly, the bottom boxes represent the nested and interacting levels of biological organization "inside" the brain and body that respond to, and shape, social worlds. What constitutes biological can be characterized as processes and structures within an individual that contribute to the growth, reproduction, and maintenance of the soma from conception to death. Biology is typically organized across multiple levels, including the genome, molecular interactions (such as gene expression, hormone production); integrated physiological and neurological systems (such as the cardiovascular system; the sympathetic adrenal medullary axis); organs and other tissues; and cells and cellular processes.

Social phenomena are similarly complex and multidimensional, and are illustrated by the relationships and interactions among individuals living in groups and within social contexts (families, neighborhoods, schools) who share the norms, institutions, and hierarchies that structure them. The social realm can also include aspects of the physical environment of relevance to biology (such as exposure to environmental contaminants, public space for recreation) that are structured by social relations and hierarchies.

A biosocial perspective, therefore, draws on models and methods from the biological, medical, behavioral, and social sciences. It conceptualizes the biological and the social as mutually constituting forces, and blurs boundaries between phenomena inside the body and outside of the body. It implies that attempts to understand one without the other are incomplete. It is a transdisciplinary approach to understanding human development, behavior, and health, developed and applied by scholars that often have disciplinary backgrounds in anthropology, psychology, epidemiology, sociology, economics, public health, genomics, medicine, and demography. 
Ongoing calls for a more integrative, multimethod, multilevel interdisciplinary approach to research on human development, health, and social inequality underscore the importance and potential contribution of a biosocial perspective (Halfon and Hochstein 2002; Harris 2010; Weinstein, Vaupel, and Wachter 2007). The recent expansion of methodological options for collecting biological samples in nonclinical settings has facilitated this effort, and innovative biological measures are increasingly being incorporated into social science research designs and data collection efforts. A new generation of biosocial research is poised to bridge the gap between community- and clinic-based approaches to understanding the dynamic interplay of biology and social context across the life course.

\section{Integrating Biology into the Social and Behavioral Sciences}

Why should social and behavioral scientists care about biology? Although we recognize that most, if not all, social and economic outcomes have some biological component, social scientists - with a few notable exceptions-have generally not considered biological processes with specificity or depth. This position does not always derive from theoretical or epistemological stances, and is often due to gaps in data, constraints of training and motivational structures that are set within disciplinary frameworks, and logistical challenges associated with collecting biological measures in nonclinical settings. Many of these gaps are narrowing.

Putting the bio in biosocial has the potential to make important contributions to the social and behavioral sciences for several reasons. First, humans are biological creatures, embedded in families, social networks, communities, and cultures. Context matters to human biology, and engagement with biological concepts and measures reflects this reality. This is especially clear in the case of human health, where the importance of social determinants is well established and widely known (Adler et al. 1994; Glass and McAtee 2006; Link and Phelan 1995), and where social impacts on underlying physiological processes are apparent and increasingly elaborated (Uchino, Cacioppo, and Kiecolt-Glaser 1996; Yang et al. 2016). Attention to biology has the potential to illuminate mechanisms through which socioeconomic, demographic, and psychosocial factors shape human development and health within the context of everyday life.

The importance of context to human biology is evident across multiple time dimensions (Lasker 1969). In the short term, homeostasis and allostasis-processes of adaptation to changes in current or anticipated environments (McEwen 1998; Sterling and Ayer 1988) facilitate physiological or behavioral responses to the shifting demands and opportunities of local environments. For example, a perceived danger or social threat increases the production of cortisol, a hormone that plays a central role in mobilizing the body's response to stress. When the threat is removed, cortisol production returns to baseline (Gruenewald et al. 2004). But repeat, or chronic, exposure to adverse environmental conditions can reset regulatory set points, resulting in "wear and tear" on key physiological systems (Seeman et al. 2001). Lower socioeconomic status-a source of chronic stress-is associated with high cortisol in the evening and with a flatter rhythm of production across the day relative to the normative pattern of declining cortisol production over the day to low levels in the evening (Cohen, Schwartz, et al. 2006; DeSantis et al. 2007). Longer term effects of environments on biological systems emerge from critical or sensitive periods of development, when exposures can have disproportionate, enduring effects on biological structure and function. Continuing with the example of cortisol, individuals born with a lower birth weight have elevated cortisol in adulthood (Phillips et al. 2000), pointing toward a biological mechanism through which lower socioeconomic status (a strong predictor of lower birth weight) may affect health within and across generations.

By getting "under the skin," biological measures provide direct, objective information on pathophysiological processes that contribute to the emergence of disease, before clinically diagnosable disease is evident. For example, relative levels of blood pressure-a robust indicator of future risk of cardiovascular disease- - tend to track from childhood into adulthood (Berenson et al. 1995; Li et al. 2004). 
Although measuring blood pressure in childhood or young adulthood will reveal few clinical cases of hypertension, it will identify individuals most at risk for the future development of cardiovascular disease and early death (Nguyen et al. 2011). Biological measures therefore enhance our understanding of how social environments influence pre-disease pathways and provide opportunities for intervention prior to the emergence of clinical disease.

Attention to biology can also identify which aspects of social and physical environments are most detrimental to health and socioeconomic well-being, as well as point toward resiliency and protective factors that buffer groups of individuals from the effects of adverse environments. The concept of embodiment has been invoked repeatedly in the social sciences to underscore the social and political nature of the human body and its responsiveness to social and cultural context (Gravlee 2009; Krieger 2005; Scheper-Hughes and Lock 1987; Seligman 2014). The body tells stories - literally and figuratively - and biological measures offer opportunities to access information that reflects the quality of social environments. Recent work on "skin deep resilience" provides a case in point: among African Americans from low socioeconomic status (SES) backgrounds, measures of self-control predict better psychosocial outcomes, such as lower depression or lower likelihood of substance use, but worse physical health outcomes, as revealed by several biological measures (Brody et al. 2013; Miller et al. 2015). Biological measurement may therefore add an important dimension to our understanding of health; that is, self-report, psychosocial, and biological measures may tell different stories. They may be particularly useful in settings where accurate self-reports are especially difficult to obtain, such as in research with children, or across international settings where linguistic or cultural factors may contribute to variation in perception, experience, or reporting (Hahn 1995; Kleinman 1986).

Social factors affect biological process and health outcomes, but the reverse is also true. For example, lower birth weight-a biological variable reflecting the quality of the prenatal environment, which is in turn shaped by genetic, developmental, and social factors-has adverse effects on cognitive development and adult educational attainment (Conley and Bennett 2000; Figlio et al. 2014). Education level is also a partial function of inherited genotype, and common genetic factors can account for some of the well-established association between education and health (Boardman, Domingue, and Daw 2015; Okbay et al. 2016). Biological processes, therefore, influence individual life course trajectories, shape social and educational attainments, and inform selection into social and physical environments that can feed back onto biological processes. When scholars do not consider how biological mechanisms shape developmental outcomes, or interact with social environments to influence social stratification across the life course, models may be incomplete or misspecified, parameter estimates of environmental effects overstated, and results biased.

A biosocial perspective is also important for translating social science research into policy. As noted, biological measures can reveal the quality of social conditions, and in some cases may motivate action to improve conditions to prevent disease rather than treat individuals already on the path toward disease. For example, lead screening in children can be used to inform housing policy, where initiatives aimed at reducing lead exposure can prevent the development of costly cognitive and behavioral disorders. Consistent evidence on the importance of social relationships for biological processes affecting health suggests that routine health screenings should include questions about the quantity and quality of individuals' social connections, and physicians should be encouraged to ask their patients about their relationships as part of their annual wellness check-ups (Yang et al. 2016).

Biological measures can also add important dimensions to the evaluation of social policies. For example, the Moving to Opportunity demonstration project was initiated in 1994 to investigate the impact of residential contexts on educational attainments, income, and overall well-being. Families in public housing were randomized into an experimental condition that subsidized their move into a low-poverty neighborhood; controls were not offered new assistance. The intervention had limited effects 
on education and income-the outcomes of primary interest when the study was designed-but large impacts on health: assignment to the low-poverty group resulted in a 13 percent to 19 percent reduction in obesity and 22 percent reduction in diabetes relative to the control group (Ludwig et al. 2011). A biosocial approach to policy evaluation can identify the biological processes and pre-disease pathways that are affected by contextual factors like neighborhood poverty, and point toward social programs that improve health. Given the high costs of health care, this kind of information may add an important, but often overlooked, component to cost-benefit analyses of social policies.

\section{The Importance of "Socializing" Biology}

The biosocial approach occupies an important and expanding space in the social and behavioral sciences, where the emphasis has been on integrating biological concepts and methods into research designed to address questions of interest to social and behavioral scientists (Harris 2010; Weinstein et al. 2007). Less appreciated is the opportunity we have to colonize the biological sciences-as well as public discourse regarding the determinants of health-to have an impact on how we conceptualize and study human biology.

For the most part, research in the biological sciences privileges explanations "inside the body," and is speeding down a reductionist road that elaborates cellular and molecular processes while ignoring contextual influences outside the body (Lewontin and Levins 2007). As just one example, the sequencing of the human genome, accomplished in 2003, was celebrated as providing "the first glimpse at our own instruction book," and "the possibility of achieving all we ever hoped for in medicine." ${ }^{2}$ Clinical medicine also privileges reduction, seeking to isolate single, proximate factors as causes of disease and as targets for treatment. Pathogens cause infection. Tumors cause cancer (Ahn et al. 2006).

In contrast, for more than a hundred years, social scientists have documented the impact of contextual factors on human development, physiology, and health. For example, in the early 1900s, the anthropologist Franz Boas showed that cranial form-at the time interpreted as a fixed, inherited marker of racial identity-was in fact malleable, and that it changed within a single generation of immigrants to the United States in response to environmental influences (Boas 1912). For more than forty years, social scientists and social epidemiologists have reported that interpersonal relationships affect health, and that social isolation is a risk factor for early death that is comparable in magnitude to established risk factors such as smoking, obesity, and lack of physical activity (House, Landis, and Umberson 1988). More recently, social isolation has been associated with physiological dysregulation in all stages of human development, pointing toward biological mechanisms through which social relationships affect health (Yang et al. 2016). Socioeconomic status-of keen interest to many social scientists-is consistently associated with multiple measures of physiological function, morbidity, and mortality (Adler et al. 1994; Yang et al. 2017; Wolfe, Evans and Seeman 2012).

Human biology is a social biology and it is probably up to social scientists to make this point. Biosocial research, conducted in diverse, community-based settings, encourages an epistemological shift that reframes human biology, development, and health as complexly determined by multiple forces inside and outside the body. It engages issues and processes of interest to biological scientists, but foregrounds social and contextual factors as potentially important contributors to variation in human physiological function and health (Stinson, Bogin, and O'Rourke 2012). This should be familiar ground for developmental and social-behavioral scientists who have long emphasized the complex interplay of genes, biology, and society across the life course (Engel 1978; Glass and McAtee 2006; Gottleib 1991; Shanahan and Boardman 2009). With an increasingly sophisticated toolkit for integrating biological measures into community-based, social science research, the

2. "What They Said: Genome in Quotes," BBC News Science/Nature, June 26, 2000, http://news.bbc.co.uk/2 /hi/science/nature/807126.stm (accessed October 4, 2017). 
time is right for a new generation of biosocial scholarship that enriches both the biological and the social sciences and helps build stronger links between them.

\section{Methodological Developments}

Historically, community- and population-based research in the social sciences has relied on vital records or self-reported, survey-based measures of health and disease. Information can be readily collected from large representative samples across a wide range of settings, but insight into biological processes is limited. In contrast, biomedical research employs indepth biological measures collected in controlled clinical or laboratory settings, but typically relies on smaller, select groups of participants who are invited to participate based on preexisting criteria. Generalizability and external validity are limited, and social factors are generally not considered, beyond standard measures of socioeconomic status or selfreported health behaviors.

Methodological options for collecting and generating biological data have expanded greatly over the past fifteen years, allowing us to bridge this gap (Weinstein et al. 2007). Lowcost, field-friendly options for collecting blood, saliva, or urine in the home or local community allow investigators to gain access to physiological information from large numbers of participants in naturalistic settings (Adam and Kumari 2009; McDade, Williams, and Snodgrass 2007). Developments in assay technology have facilitated the measurement of proteins, gene transcripts, epigenetic marks, and DNA sequences with higher resolution in smaller quantities of sample, at lower costs (Dedeurwaerder et al. 2011; McDade et al. 2016). Portable devices and low-cost monitors facilitate assessment of sleep, physical function and activity, blood pressure, and body size and composition (Lindau and McDade 2007; Marino et al. 2013).

These methodological innovations have encouraged wide-scale integration of objective biological measures into social science surveys. For example, dried blood spots-drops of whole blood collected from a simple finger stickhave been collected from more than thirty-five thousand participants in the United States in studies such as the National Longitudinal Study of Adolescent to Adult Health (Add Health), the Health and Retirement Study, the National Social Life, Health, and Aging Project, and Moving to Opportunity. International studies, including the Cebu Longitudinal Health and Nutrition Survey, the Mexican Family Life Survey, and the Study on Global AGEing and Adult Health are collecting tens of thousands more. In another example, Add Health developed its own kit for the collection of buccal cell DNA in 1996 to test for the zygosity of sampled twin pairs. Ten years later, commercial kits for saliva DNA collection (such as Oragene) are routinely used by multiple studies to collect thousands of DNA samples both in the home setting and through the mail via self-collection.

The integration of objective measures of biological function and health has advanced the biosocial perspective by directly contributing to our understanding of how social, economic, and community factors shape human biology and health, and vice versa. These methods also address the goal of socializing biology. By taking our methods into the community, where participants are living their daily lives, we greatly expand the range of environmental variation that can be evaluated in relation to biological phenomena. Contextual factors are therefore brought into relief as potentially important determinants of human physiological function and health in ways not possible with lab- or clinic-based research designs. Last, these methods serve as a catalyst for productive collaboration among social, life, and biomedical scientists. The growing availability of social and biological data in large, representative samples, and the emphasis on interdisciplinary scholarship, has laid fertile ground for the integration of complementary expertise to generate novel insights into the ways in which social and biological processes interact in pathways of human development.

\section{THE IMPORTANCE OF THE LIFE COURSE}

Human development has social and biological determinants and intergenerational linkages beginning in utero and continuing throughout all stages of the human life span (Hertzman and Boyce 2010). Despite a consensus that early 
life conditions and childhood experiences matter for subsequent social and biological development in adolescence, early adulthood, mid-adulthood and old age, most social and biomedical research does not capture the ways in which developmental processes are linked and interrelated across phases of human life, nor does it capture the dynamic interactions of social and biological forces that underlie development across time and space. Part of this research gap is due to a lack of longitudinal, multilevel life course data and intergenerational study designs, and part to disciplinary approaches designed to identify disciplinaryspecific determinants of social, behavioral, or health outcomes at a point in time.

A life course perspective is essential in biosocial research because outcomes at any point reflect the product of prior interactions between social and biological forces that occur across human development (Shanahan, Hofer, and Shanahan 2003). Life phases and social roles are often intimately tied to biological events or trajectories (George 2009). For example, a woman's first birth marks her transition into parenthood just as menopause defines the end of the reproductive phase of her life. Although a woman can biologically become a mother when she reaches puberty in adolescence, most young people in the United States delay parenthood until well after puberty to continue social and emotional maturation and invest in human capital and career development before becoming a parent. Thus, social and biological forces jointly shape transitions between roles and patterns of continuity and discontinuity that extend across the phases of life. Biosocial approaches, therefore, require the researcher to dynamically assess both biological and social features of the developing person and their changing social context through time and across generations to achieve a full understanding of the determinants of social and physical well-being.

\section{Biosocial Processes Across the Life Course}

Within social and behavioral sciences, research on aging has been at the forefront of biosocial approaches. Because aging integrates forces inside the body and outside the body to shape function and health in older adulthood (figure
1), aging research has led the field in study designs incorporating inputs across social and biological levels of analysis. Understandably, this line of research focuses on phenomena such as disability, illness and disease, and longevity and mortality. The biosocial approach in aging research, however, has not been wellinformed by a life course perspective.

For a long time, aging research used selfreported health and behavioral information and cross-sectional designs to study, for example, the age distribution of the prevalence of illness and chronic disease (see, for example, National Center for Health Statistics 2016; Ward, Schiller and Goodman 2014), activities of daily living and instrumental activities of daily living designed to assess whether older adults can independently care for themselves (Freedman and Spillman 2014), and family and social relationships among the elderly (Waite and Das 2010). Demographic studies also use cross-sectional data but dynamic life table methodology to document onset and years of disability and chronic illness and to estimate mortality risks and life expectancy based on point-in-time rates of these respective events (Crimmins, Zhang, and Saito 2016). Perhaps the most influential contribution of aging research with implications for the biosocial paradigm is long-standing evidence of large and persistent social gradients in health and mortality (Adler et al. 1994; Wolfe, Evans, and Seeman 2012; Marmot and Wilkinson 2005). Still, this research remains primarily cross-sectional, documenting how SES is associated with aging-related outcomes at a given point.

With the advent of nationally representative longitudinal aging studies in the 1990s, such as the Health and Retirement Study (HRS) and the National Social Life, Health and Aging Project (NSHAP), and longitudinal communitybased aging studies, such as Framingham, Atherosclerosis Risk in Communities Study (ARIC) and Reasons for Geographic and Racial Differences in Stroke (REGARDS), a life course design could now be applied to understand how previous social, behavioral, and environmental conditions were related to health and disease outcomes among older adults. In addition, as new survey field methods for measuring objective health outcomes were incorporated into many 
of these ongoing longitudinal aging studies, the ability to understand biological mechanisms and markers of health and disease further enhanced longitudinal life course data for biosocial research. However, the life phase examined in these studies is still limited to older adults because observations begin when individuals are forty-five (ARIC) or fifty (HRS) or fifty-five (NSHAP), thus missing earlier life stages that certainly bear on aging processes that arguably begin at birth. The social gradient in health and mortality, for example, can now be studied by examining how SES trajectories beginning at age fifty influence the onset of disease or death.

From a life course perspective, this research design has four major limitations. First, SES does not change much beyond age fifty because the components of socioeconomic status-education, occupation, income and wealth-are typically developed earlier in the life course during adolescence, early, and mid-adulthood and vary little in old age. Second, the early and midlife biological precursors to disease onset and death are not observed in these studies. Relatedly, the lack of biological data from earlier ages precludes opportunities to consider how early life course health and biological processes shape SES attainments in adulthood. Fourth, studies that begin observation at older ages miss those who have died, typically the more disadvantaged individuals who have been more exposed to earlier life trauma and illnesses and have fewer resources for health care, thus biasing the SES-health relationship. One solution to this lack of prior life course information that bears directly on older age social and physical well-being is to collect retrospective information about status earlier in life, enabling a modified life course perspective for biosocial research. Here aging studies have focused on retrospective reports of SES and health conditions at birth and during early childhood.

Along these lines, research on the developmental origins of health and disease (DOHaD) has exploded, following early biomedical research by Barker documenting significant links between birth weight and later cardiovascular disease risk within cohorts (Barker 1997, 1998, 2006). The life course approach has had a ma- jor impact on epidemiologic research on the determinants of adult disease risk, with a particular emphasis on cardiovascular diseases and the physiological processes through which they are influenced by early life nutritional environments (Gluckman et al. 2008; Wadhwa et al. 2009, Smith and Ryckman 2015; Kuh and Ben-Shlomo 2004). Numerous studies have linked uterine, birth, and childhood exposures to adult physical health and disease (Bengtsson and Broström 2009; Cameron and Demerath 2002; Crimmins and Finch 2006; Smith and Ryckman 2015). Demographic and social research on the "long arm of childhood" has also demonstrated the value of a life course perspective when early life circumstances are both directly and indirectly associated with health outcomes that emerge decades later in adulthood (Blackwell, Hayward, and Crimmins 2001; Case and Paxson 2010; Elo and Preston 1992; Hayward and Gorman 2004; Preston, Hill, and Drevenstedt 1998).

Most of this research, however, links early life conditions with physiological processes or chronic disease outcomes in later adulthood with cross-sectional research designs, paying limited attention to what happens in betweenduring the majority of the early life course from later childhood to adulthood. From a biosocial perspective, this means we are missing a lot, especially the social processes and contexts that structure, mediate, and moderate biology over the life course.

Adolescence and the transition to adulthood, for example, are life stages when young people first begin to choose their environments, health behaviors, habits, and future lifestyles (Harris 2010). These life course choices shape or alter social and biological pathways originating in childhood and moving into adulthood. Investments in human capital begin in early childhood, but intensify and become more self-directed during adolescence and the transition to adulthood. Profound and protracted physical, biological, and neurological changes linked to puberty occur throughout adolescence and early adulthood. Hormonal changes prompt a literal remodeling of cortical and limbic circuits in the brain that were previously organized in the perinatal period and that, in combination with adolescent social ex- 
periences and contexts, affect general cognition, decision making, and behavior into adulthood (Sisk and Zehr 2005). Behavioral changes and exploration in diet, exercise, sleep patterns, substance use, sexual activity, and aggression during adolescence and young adulthood further shape social and biological pathways into adulthood (Hubert et al. 1987). DOHaD research, and other life course perspectives, ideally should include the contributions of these critical developmental stages to illuminate health and well-being pathways into adulthood.

Although neurological development and change slows down as young people settle into adulthood, these demographically dense years bring new stresses to daily life as young adults juggle the multiple interrelated life domains of relationships, schooling, work, and family. Stress processes are perhaps the most commonly considered biological mechanisms through which the social environment gets under the skin to affect health and development in biosocial models, as described earlier in the case of the stress hormone cortisol (Gruenewald et al. 2004; McEwen and Lasley 2002). Middle adulthood may usher in greater life course stability and security in socioeconomic status, work, and family, but only for certain subgroups of the population. Middle adulthood has become more dynamic and demanding in contemporary U.S. society-high divorce and repartnering rates, greater dependency from both the child and parent generations, and uncertain work schedules, low wages, and a lack of employment benefits for those with low education or few job skills. Relative to other life stages, middle-aged adults are highly embedded in social relationships with aging parents, children, the parents of children's friends, neighbors, work colleagues and within community institutions. These relationships are important social mechanisms that can buffer (through social support) or exacerbate (through strain and conflict) the daily stresses of middle adulthood (Yang, Schorpp, and Harris 2014; Yang et al. 2016).

All life course stages have unique social and biological forces that determine life-long human development and that operate independently and jointly to influence physical and so- cial well-being in that life stage and beyond. Biosocial research cannot examine social and biological forces in all life stages in one project or with one dataset, but should contribute knowledge about how social and biological phenomena operate in distinct life stages and are linked to health and social inequities in subsequent stages across the life course. Although we have made some progress documenting the association between early life conditions and late life health and disease outcomes (such as lower birth weight and increased cardiovascular disease risk), we need to move beyond cross-sectional designs to uncover the underlying life course processes that explain these associations. Both the intergenerational precursors that lead to these conditions and the subsequent intragenerational life course pathways such conditions initiate are yet to be explored. However, a small but growing literature links these kinds of early life health factors to later social attainments, but more research on health and biology as underlying factors in social stratification processes is needed.

Biosocial Study Designs of Health and Social Inequality Across the Life Course

Here we describe two general life course orientations for understanding how biological phenomena are related to social and economic status and opportunities in direct, indirect, and reciprocal ways. One orientation examines how social stratification processes across the life course are related to subsequent health outcomes in different life stages. This orientation stems primarily from the large literature on the social gradients of health discussed (or more commonly, the social determinants of health), but with a life course perspective. Social stratification is both an inter- and intragenerational process. At birth, we enter a social hierarchy tied to parental SES that determines access to material and social resources for both physical and social development. The developing individual then faces constraints and opportunities in each life stage that determine social and economic status across time. Inter- and intragenerational social stratification processes have both direct and indirect effects on health across the life course. Understanding the social and 
biological mechanisms for how social stratification processes get under the skin to influence health is at the heart of this conceptual orientation of biosocial research.

Ideally, social stratification is measured longitudinally, as a life course process, conceived as social exposures that can be positive (supportive parenting behaviors, college education) or negative (childhood poverty, neighborhood disadvantage). Exposure to both beneficial and adverse experiences over the life course will vary for each individual and constitute a unique social stratification trajectory. Biological outcomes are conceived of as the consequence of exposure in social stratification trajectories and can be measured at a point in time in a particular life stage or over time as biological and developmental change. Importantly, social stratification trajectories represent social processes that enable the biosocial researcher to explore fundamental life course mechanisms involving the timing, duration, and intensity of beneficial or adverse social exposures that occur in different and across phases of life and that affect health and development in subsequent life stages. The ability to measure the timing, duration, and intensity of social exposures across the life course allows for testing life course models for how social experiences that occur outside the body are linked to biological mechanisms inside the body that affect health and well-being.

The stress response framework is the most prominent biosocial paradigm to explicate how trajectories of social structural inequalities are associated with greater exposure to stress and its biological and health-related manifestations (Pearlin 1989; Aneshensel 1992; McEwen 1998; McEwen and Lasley 2002). When social exposures are intense, or the magnitude of structural disadvantage is high (depth of poverty, multiple disadvantages of poor neighborhoods), stress response is chronic and biological dysregulation is greater, resulting in poor health and developmental outcomes. The life stage timing of social exposures, however, may differ for both the biological mechanisms and subsequent health outcomes associated with stress exposure. Figure 2 provides an illustration of various life course models that describe how exposure to social disadvantage in partic- ular developmental periods may operate to increase health risk in subsequent life stages.

The top model illustrates sensitive period timing effects in which exposures during sensitive periods of development have stronger effects on health outcomes than they would at other life stages (Hayward and Gorman 2004; Gluckman et al. 2008; Cohen, Janicki-Deverts et al. 2010). Sensitive period effects operate through a biological embedding mechanism whereby social exposures during sensitive windows of development have the potential to induce structural and functional changes to the developing individual through biological programming that cannot be reversed regardless of intervening experience. Thus, the dark shadowed line represents a direct effect of exposure in the earlier stage of development with no indirect effects and no direct effects of subsequent social disadvantage on later life health. This life course model posits that the effect of the sensitive period exposure is typically latent in that its impact on health outcomes may not appear until later life stages, often decades later.

Duration effects of social stratification processes can be explored through the accumulation life course model (middle model of figure 2), which emphasizes the role of persistent advantage or disadvantage over time-both in specific life stages and over life stages-on health and development. The effects of multiple exposures over the life course are both additive and interactive and combine in synergistic ways to influence biological mechanisms and, in turn, health and development outcomes. Cumulative effects can either be multiple exposures to a recurrent stressor (such as chronic poverty) or a series of exposures to different social environments or life experiences. For example, poverty experienced only during childhood is not as detrimental as poverty during childhood, adolescence, and the transition to adulthood on subsequent adult health.

A third life course model that might explain how social stratification processes are related to health outcomes is the pathway model, which tracks how social exposures in one life stage influence the probability of related social exposures in subsequent stages. Also known as the chains of risk model, it emphasizes pathway 
Figure 2. Life Course Models of Social Disadvantage Trajectories and Health
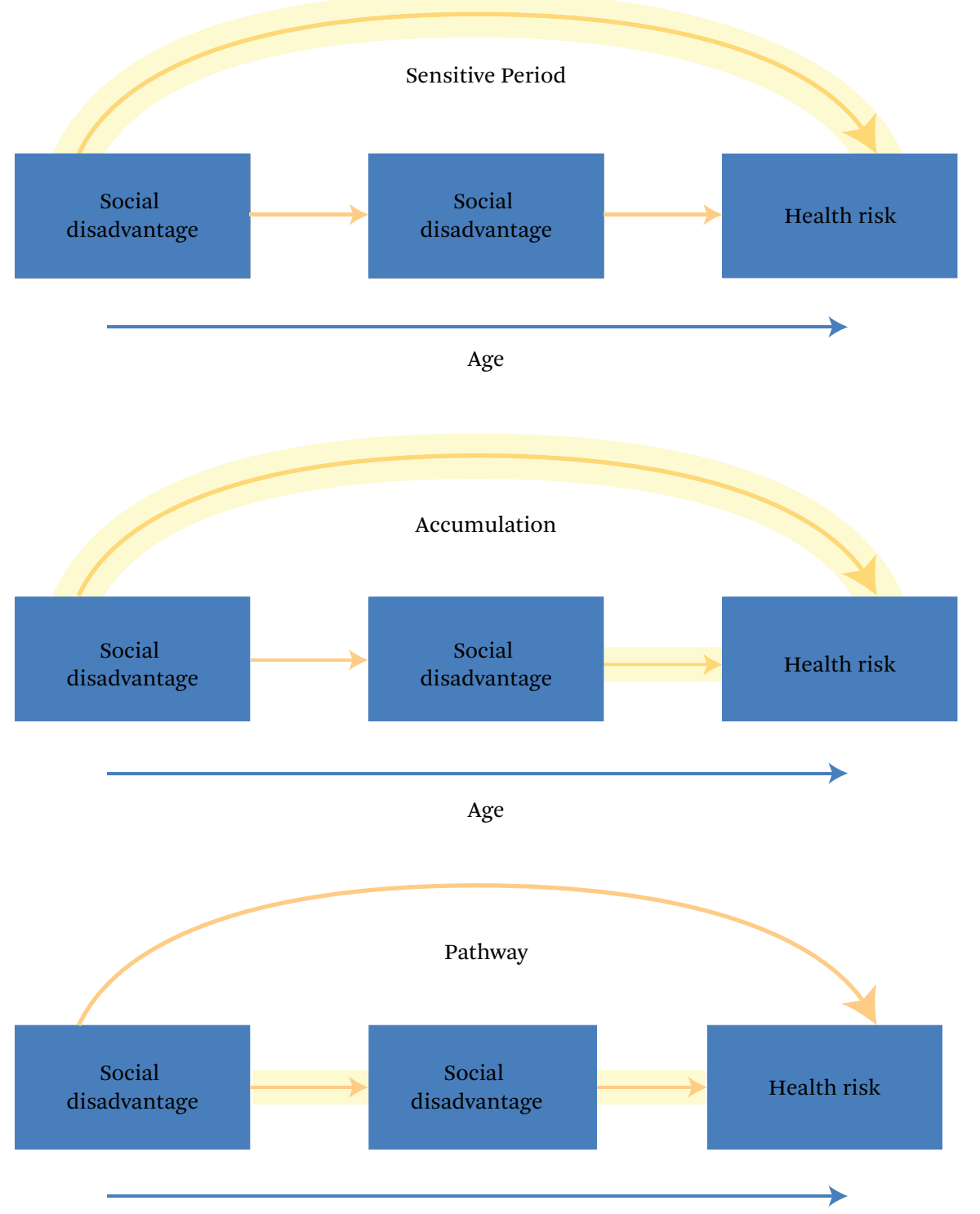

Source: Authors' compilation.

effects whereby early experiences set in motion a chain of events that put individuals on paths differentiated by types and levels of stress exposures to social and biological factors (Marmot et al. 2001; Pudrovska and Anikputa 2014). This model elaborates on the ways in which inter- and intragenerational social stratification pathways are linked across the life course. For example, the connection between early life conditions and adult health and disease may be explained by the SES pathway where early life SES determines adult SES, which in turn, is a more proximate and important predictor of adult health and disease (Yang et al. 2017).

A second orientation for understanding biosocial pathways in well-being across the life course is consideration of the role of biology or health in social stratification processes (Palloni 2006). In this orientation, biological mechanisms and health trajectories are important 
Figure 3. Role of Health in Social Stratification Processes

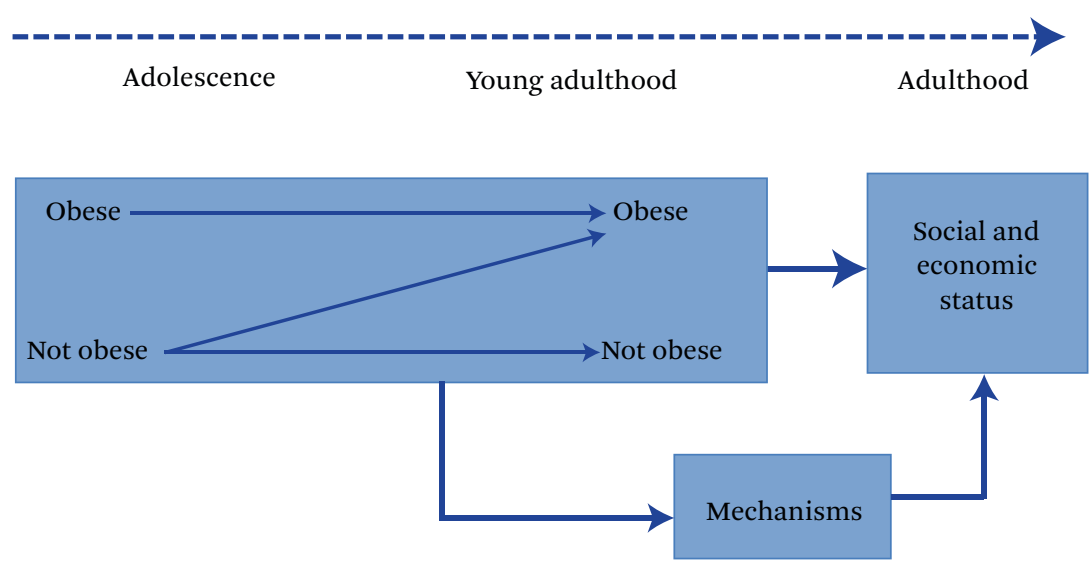

Source: Authors' compilation.

contributors to subsequent socioeconomic outcomes and attainment. For example, economic research has focused on how childhood health influences human capital and labor force outcomes in adulthood, including educational attainment, labor force participation, income, and occupation (Case, Lubotsky, and Paxson 2002; Currie and Stabile 2003; Currie and Moretti 2007; Case, Fertig, and Paxson 2005; Almond and Currie 2011). Figure 3 illustrates the case of how early life course health can influence later socioeconomic status. In particular, life course trajectories of obesity during adolescence and into young adulthood contribute to social stratification outcomes in adulthood. Research findings indicate that those who become obese in early adolescence and remain obese for a longer period of time have lower levels of education, marriage, wages, household income, employment, assets, and subjective social status (Cawley 2004; Han, Norton, and Stearns 2009; Harris and Lee 2011; Glass, Haas, and Reither 2010). These life course effects of obesity operate through such mechanisms as low self-esteem, social isolation, societal views of attractiveness and lost work days, illustrating the biosocial connections. Similar effects are found for chronic health conditions and diabetes during adolescence and young adulthood, which truncate educational trajectories and reduce the stability of work (Fletcher and Richards 2012).

In this orientation, life course models will illuminate the often missing, underlying role of biology in social stratification processes. Understanding whether, when, and how biological processes matter for social and economic outcomes across the life course will help identify when biomedical interventions might be most effective for reducing social inequality. These models are not mutually exclusive and in reality coexist (see Hallqvist et al. 2004). Most important, they provide a framework for biosocial research made possible by longitudinal data and study designs that enable researchers to identify the social and biological processes that operate in pathways of well-being across the life span. The life course perspective articulates the longitudinal and multidimensional of social and biological forces that operate in all life stages and underlie human development across time, emphasizing the need to conceptualize social conditions and biological mechanisms as dynamic constructs that unfold across time, beginning in early life and continuing into young adulthood, midlife, and old age.

\section{SOCIAL GENOMICS}

Consensus is now widespread that social, behavioral, and health outcomes are a function of both nature and nurture, and are best understood in a life course context. Even in the age of genome mapping, research on the impact of genetic variance alone has limited explanatory power, and is often of less interest to social and behavioral scientists given that in- 
dividual DNA sequence is fixed and not subject to intervention. Instead, social and behavioral scientists have been drawn to understanding gene-environment interplay, or how environmental and genetic factors interact over time to affect social, behavioral, and health outcomes, along the lines of figure 1 . Because such outcomes represent the cumulative history of a person's social experiences as they combine with genetic makeup, gene-environment interplay reflects life course processes. Although appreciation is widespread that the links between genes and behavioral outcomes, for example, are conditioned by the social environment, consideration of the dynamic features, of social environments and life experiences as processes occurring across the life course is not. To date, most studies of gene-environment interplay are cross-sectional or use longitudinal data without explicit modeling of life course features, including pathways, transitions, trajectories, durations, or timing (Conley 2016; Shanahan and Boardman 2009).

Nevertheless, substantial social science research examines gene-environment interplay focusing on two general approaches: geneenvironment interactions (GxE) and geneenvironment correlations (rGE). GxE research has captured social science attention by elaborating on processes by which the effect of genetic factors on a social or biological outcome is conditioned by environmental factors and vice versa (Boardman, Daw, and Freese 2013; Hutter et al. 2013). Provocative findings have been published, for example, showing that genetic effects on children's cognition are dampened in low SES environments, genetic propensities for adolescent substance use are enhanced or suppressed according to the prevalence of substance use in the adolescents' schools, stressful life events increase the risk of depression depending on one's genetic profile for processing neurotransmitters, and adolescents are more genetically similar to their friends in more highly structured and segregated environments (Boardman, Domingue, and Fletcher 2012; Caspi et al. 2003; Rowe, Jacobson, and Van den Oord 1999; Daw et al. 2013). Although such findings highlight the important role of the social environment in genetic processes, especially from a policy per- spective, GxE research has come under significant criticism for a poor record of replication, lack of statistical power for GxE associations, and the endogenous nature of most measures of E (Boardman, Daw, and Freese 2013; Conley 2016; Freese and Shostak 2009; Charney and English 2012; North and Martin 2008). Still, promising GxE research is on the horizon using natural or quasi-experimental designs and larger samples afforded through genetic consortia (see, for example, Boardman et al. 2012; Okbay et al. 2016; Schmitz and Conley 2016, 2017; Rietveld et al. 2013).

Research exploring gene-environment correlations is especially valuable to social and behavioral sciences because it confronts the worrisome endogeneity problem of estimated environmental effects being due to unobserved heterogeneity (genetic factors) associated with the selection of one's environment. Geneenvironment correlation (rGE) refers to processes by which genetic factors are associated with features of the environments in which individuals live their lives (friendships, peer groups, romantic relationships, schools, neighborhoods, work environments, and so on). Sorting out and controlling for genetic variance in selection of these environments enables social and behavioral scientists to isolate the causal impacts of social environments on social, behavioral, and health outcomes. In sum, perhaps the main impact of the evidence on gene-environment interplay has been to dispel notions of the nature-nurture dichotomy and build consensus on the need for integrative models of genetic and social factors to better understand human development and health. But two general weaknesses remain: the G (genotype) is still fixed and therefore unresponsive to social change; and the dynamics of life course changes and their biological interactions with changing social environments and experiences over time have not been exploited in either GxE or rGE research.

Human social genomics, on the other hand, is an emerging field of research that examines why and how external social conditions affect the activity of the genome (Slavich and Cole 2013; Boyce and Kobor 2015). Social genomics includes the study of gene expression (transcriptome) and epigenetics (epigenome). It 
emerges from the scientific understanding that while the gene sequences we inherit from our parents are fixed, the expression of these genes is shaped by forces "outside" the body. The focus of social genomics is inherently biosocial as it seeks to uncover how social experiences can alter gene expression and thereby affect physiological function and social and behavioral outcomes (Cole 2014; Hertzman 2012). Indeed, human social genomics research is demonstrating that certain genes can be "turned on" or "turned off" by different social-environmental conditions, and in some cases these social exposures can affect the activity of hundreds of genes in a coordinated manner.

This line of research provides new opportunities for understanding how social and genetic factors interact to shape complex biological and social pathways of well-being. Indeed, it has the potential to reframe our understanding of the genome as a dynamic substrate that incorporates information from the environment over developmental time, rather than the prevailing view of the genome as static sequences of DNA that are fixed at conception. Current social genomics research has examined, for example, how social processes, such as social status, social supports or isolation, social capital, early life adversity, exposure to toxicants and microbes, and health behaviors, alter the expression of hundreds of human genes (such as suppression of antiviral and antibody-related genes and stimulation of pro-inflammatory genes) to affect human development and health over many years (see, for example, Cole 2013, 2014; Murphy et al. 2012; Miller et al. 2009; Fry et al. 2012; McDade et al. 2017).

The term epigenetics - first used by Waddington in the 1940s (Jablonka and Lamb 2002)literally means above or on top of genetics, and refers to chemical modifications to DNA and its packaging that change the accessibility of gene regions to transcription factors, and thereby affect the level of transcription. These modifications alter the physical structure of DNA in ways that are relatively stable and conserved with cell replication. Therefore, epigenetics represents a biological mechanism through which the body "remembers" prior environmental exposures to shape gene expres- sion-a key reason why epigenetics has captured the attention of many social scientists. Methylation of DNA has been the major focus of human research, and involves the binding of methyl groups to cytosine residues in $\mathrm{CpG}$ dinucleotides (Bird 2002). At a point in an individual's life course, analysis of DNA methylation may reveal how and which genes have been modified in response to the cumulative life course environmental, behavioral, and biological trajectories of that individual. Thus, epigenetics specifies a life course biosocial process that entails the dynamic interactions and feedback loops of social and genetic phenomena both inter- and intragenerationally over the life course (Boyce and Kobor 2015). For example, epigenetic patterns have been shown to be altered by a range of environmental conditions such as diet, tobacco smoking, exercise, and exposure to chemicals (Christensen et al. 2009; Grönniger et al. 2010; Langevin et al. 2011). More broadly, measures of socioeconomic and psychosocial adversity in childhood have been linked to patterns of DNA methylation later in life (Essex et al. 2013; Needham et al. 2015). Epigenetic patterns have also been shown to affect physical traits and appearance, behavior, and health outcomes (IHEC 2013). Thus, environmental variation may routinely change epigenetic patterns, and those epigenetic patterns may in turn influence developmental outcomes over time.

One of the more provocative-but also controversial-findings for social scientists is that environmentally triggered behavior or biological change might be transmitted across generations through epigenetic mechanisms and without the involvement of DNA sequence (Jablonka and Lamb 2015; Thayer and Kuzawa 2011). Fascinating early evidence on the inheritance of epigenetic marks comes from research done on mice. Human evidence is much more difficult to establish. Studies of humans whose ancestors survived through periods of starvation in Sweden and the Netherlands suggest that the effects of famine on epigenetics and development can pass through at least three generations (Heijmans et al. 2008; Tobi et al. 2009). Nutrient deprivation in a recent ancestor seems to prime the body for diabetes and cardiovascular problems, a biological re- 
sponse that may have evolved to mitigate the effects of future famines. The findings on intergenerational epigenetic inheritance could have far-reaching significance. Much social science research documents how parental characteristics, such as lifestyle, behaviors, and living habits, influence children's well-being. Epigenetic processes may provide biological mechanisms through which lifestyles and behaviors are stored and transmitted to children and their children's children, who do not have any direct environmental exposure to these lifestyles or behaviors.

Social genomics is an exciting area for future biosocial research that emphasizes the instrumental role of the social environment in altering how genes are expressed to affect behavior, biology, and social and health outcomes. The more we understand how the social environment regulates genes that affect health and social stratification processes, the more potential we have for intervening on those environmental exposures to reduce health and social inequalities. The molecular models of social genomics do require new methodological skills and technical capacities for working with these data, over and above the application of standard social science methods used in GxE and rGE analysis. Interdisciplinary training, however, is already coming online to equip social scientists with these skills through summer boot camps and graduate training programs around the country. The potential for understanding these social and biological phenomena has captured the attention of the scholarly and public worlds alike. The ability of social genomics to fill diverse gaps in our understanding of human development and health and to provide scientific explanations of the mechanisms underlying our lived experiences makes it a compelling avenue for future biosocial research.

\section{ISSUE THEMES AND CHAPTERS}

Contributors to the volume represent a wide range of disciplines, and their work advances the biosocial perspective on human development, behavior, and health across the life course. The issue is loosely organized around three themes.

\section{Disadvantage, Discrimination, and Health} The impact of social adversity on human welfare is of long-standing concern to social scientists. A biosocial perspective addresses questions regarding the health impacts of adversity, and the biological mechanisms through which social environments "get under the skin" to impact human development and health. This aspect of biosocial research has been greatly advanced by recent methodological developments that have facilitated the collection of objective biological data in nonclinical, community- and population-based settings. All three articles in this section showcase the value of these kinds of measures for advancing our understanding of how social adversity affects health.

Douglas Massey and his colleagues build on a long tradition of scholarship on neighborhood effects, with a particular emphasis on residential segregation and concentrated poverty. The majority of this work has been sociological, including some links to health but paying little attention to biology. Massey and his colleagues introduce a biosocial framework for linking spatially concentrated disadvantage at the geographic level with an individual-level biological measure of cellular aging (telomere length) to reveal mechanisms through which social structure contributes to race-based differences in morbidity and mortality in the United States. Aside from contributing to the literature on neighborhood effects, the article demonstrates how collaborative, interdisciplinary teams can leverage novel insights from molecular biology to cast new light on longstanding social science questions.

The article by Bridget Goosby and her colleagues also investigates the health impact of social disadvantage, but at the individual, micro-social level of analysis. Their focus on perceived discrimination draws on a wellestablished line of biosocial research that attends to the appraisal of stress as a key part of the causal pathway linking social adversity with physical health. Sleep quality and quantity are the key outcomes in their study, based on recent clinical and epidemiological research demonstrating the importance of sleep for a wide range of physical and mental health out- 
comes. Like Massey and colleagues, the article showcases the value of borrowing from biological and health sciences to illuminate issues of interest to social scientists. This point is underscored by the counterintuitive nature of their results. Global ratings of discrimination are negatively associated with sleep quantity and quality, as one might expect, but participants slept better the night following a day when they reported a discriminatory encounter. This finding reveals the potential of biological or health-related measures to provide novel insights into psychosocial dynamics that might otherwise be obscured. It also highlights the value of measuring these dynamics at multiple levels of analysis.

The article by Elizabeth McClure and her colleagues provides an excellent example of how a biosocial approach can be used to "socialize" biology. The ratio of signal-joint to beta T-cell receptor excision circles (sj/beta-TREC ratio) is used by immunologists to measure the function of the thymus, an organ that produces cells ( $\mathrm{T}$ lymphocytes) that are essential for immunity. In their study in Detroit following the Great Recession, they show that neighborhoodlevel measures of home foreclosure and abandonment predict lower levels of thymic function among residents. Furthermore, reduced social cohesion-a product of home foreclosure and abandonment-predicts lower thymic function. With a clearly articulated conceptual model that informs their study design and analytic strategy, McClure and her colleagues move from the macro- (Great Recession) to the mezzo- (neighborhood characteristics) to the micro- (thymic function) levels of analysis to demonstrate how human biology is a social biology.

\section{Developmental and Intergenerational \\ Processes}

The two articles in this section use a biosocial approach to assess the biological and social features of the developing person and their changing social contexts through time and space to provide new insights into the determinants of social and physical well-being. The articles examine outcomes in specific life stages as a function of earlier life course exposures and inter- actions between social and biological forces that occur across human development.

Yang Qu and his colleagues use a biopsychosocial approach to understand adolescent development among a growing U.S. ethnic minority group-Mexican American youth. They identify adolescence as a dynamic life stage in which neural changes in both brain function and brain structure are likely associated with individual differences in academic and psychological adjustment. They also argue that the environment becomes especially salient during adolescence for Mexican American youth when ethnic parents attempt to socialize children about their cultural values and heritage, and at the same time, adolescents yearn to spend more time with peers and fit into adolescent social life and activities. The longitudinal research in this article examines the independent and interactive effects of adolescents' brain development and their family and peer environment in determining educational achievement and substance use. By integrating imaging data with rich social variables on cultural socialization and peer deviance, Qu and his colleagues find important independent contributions of biological and psychosocial factors in youth's achievement and adjustment.

The Margot Jackson and Susan Short article uses a life course intragenerational design to examine both gender differences in physical health in young adulthood and the ways in which adolescent development and social environments might explain those differences. Documenting gender differences in objective biological markers of health (inflammation and immunosuppression) during young adulthood is a contribution to the health disparities literature given most research on sex differences focuses on older aged populations. Jackson and Short report strong differentials in inflammation and immune function that disadvantage women in these biological systems. They explore a wealth of childhood, adolescent, and early adulthood circumstances-including demographic, family socioeconomic, health behavior, and young adult family formation and socioeconomic attainment-as potential explanatory factors underlying the sex differences. Identifying gender disparities early in 
the adult life course is critical to curbing their growth throughout adulthood by designing interventions to improve female health and reduce the disparities before chronic disease and long-term physical damage occurs.

\section{Genes and Environments over the Life Course}

Interest in gene-environment interplay has captured the imagination of biosocial researchers, who isolate the role of genes in relation to environmental influence and focus on the ways in which genes and environments operate together in social stratification processes across the life course. The advent of new sources of molecular genetic data, especially genomewide data, and statistical tools for analyzing massive amounts of individual-level genomewide data linked to survey and biomarker information in large studies has opened exciting new research opportunities for understanding gene-environment interplay in biosocial models of attainment and behavior. Two articles in this issue take advantage of an analytic approach that combines the genetic associations with specific phenotypes (that is, behavioral, attainment, and health outcomes) across the entire genome using polygenic scores (PGS) based on genome-wide association studies (GWAS). A PGS is a linear combination of the effects of genetic variants present in the entire genome specific to a phenotype that can be interpreted as a single quantitative measure of genetic predisposition for that phenotype.

The article by Melinda Mills and her colleagues builds on their recently published meta-GWAS study on human reproductive behavior (Barban et al. 2016) by examining the predictive power of two PGS discovered in that study for age at first birth and number of children ever born in four independent extant data sources. Despite extensive research on the role of genetics in such outcomes as obesity, substance use, and education, little attention has been directed to fertility behavior, perhaps because age at first birth and number of children ever born are complex outcomes related to biological fecundity, behavioral choice, and socio-environmental factors. Consistent with most of the research on genetic influence using molecular data, Mills and her colleagues find relatively low levels of predictive power for the PGSs based on the entire genome, revealing the more predominant role of socialenvironmental and behavioral factors in determining age at first birth and number of children ever born. Rather than speculating on how much environmental and behavioral estimates are overstated by their confounding with genetic effects, social scientists use these models to control for this genetic confounding while estimating the importance of social and behavioral factors of fertility behavior. Moreover, age at first birth and number of children ever born are well-established markers of social stratification, illustrated by the voluminous literature on teenage childbearing and family size (reviews in Furstenberg 2003; Powell et al. 2016; Sweeney and Raley 2014; Wilcox and Lerman 2014). Indeed, Mills and her coauthors show that the PGSs are also correlated with other fertility traits, such as childlessness, and are independent of the effects of education.

Benjamin Domingue and his colleagues focus on the role of genes in environmental selection processes, or gene-environment correlation. They examine geographic clustering of PGSs for multiple phenotypes related to anthropometry, education, and physical and mental health by state of residence at different points in the life course to explore the extent to which state-level genetic composition explains state-level clustering of various phenotypes and how these relationships change over age. Domingue and his coauthors expertly discuss the important motivation behind examining gene-environment correlations, the mechanisms through which gene-environment correlations may operate, and test for the penetrance of PGSs (association of genotype and phenotype) at both the individual and ecological (that is, state) levels. For most of the phenotypes they examine, the authors find that the ecological correlations are much larger than the individual correlations, suggesting the environmental context of the state may moderate the genotype-phenotype associations. In particular, they identify two phenotypes, depression and educational attainment, for which the genetic context of a state is especially salient. 


\section{CONCLUSIONS}

The articles in this issue advance our understanding of the biosocial pathways of wellbeing across the life course, and their complex associations with social stratification. They build on a solid foundation of biosocial research in the social sciences, and they showcase the value of blurring the boundaries between phenomena outside the body and inside the body. In some cases, they use novel methods to cast new light on old questions. In others, novel methods reframe the questions and open new lines of inquiry. In all cases, the integration of biological information with measures of social environments and behavior across the life course is generating unique insights and unprecedented opportunities for discovery. In many ways, this issue can be seen as marking the "coming of age" of a new generation of biosocial scholarship, and the future looks bright for those of us who are invested in illuminating the complex pathways linking society, biology, and health across the life course.

\section{REFERENCES}

Adam, Emma K., and Meena Kumari. 2009. "Assessing Salivary Cortisol in Large-Scale, Epidemiological Research." Psychoneuroendocrinology 34(10): 1423-36. DOI: 10.1016/j. psyneuen.2009.06.011.

Adler, Nancy E., Thomas Boyce, Margaret A. Chesney, Sheldon Cohen, Susan Folkman, Robert L. Kahn, and S. Leonard Syme. 1994. “Socioeconomic Status and Health: The Challenge of the Gradient." American Psychologist 49(1): 15-24.

Ahn, Andrew C., Muneesh Tewari, Chi-Sang Poon, and Russell S. Phillips. 2006. "The Limits of Reductionism in Medicine: Could Systems Biology Offer an Alternative?" PLoS Medicine 3(6): e208. DOI: 10.1371/journal.pmed.0030208.

Almond, Douglas, and Janet Currie. 2011. “Killing Me Softly: The Fetal Origins Hypothesis." Journal of Economic Perspectives 25(3): 153-72. DOI: 10.1257/jep.25.3.153.

Aneshensel, Carol S. 1992. "Social Stress: Theory and Research." Annual Review of Sociology 18(1): 15-38. DOI: 10.1146/annurev.soc.18.1.15.

Barban, Nicola, Rick Jensen, Ronald de Vlaming, Ahmad Vaez, et al. 2016. “Genome-Wide Analysis
Identifies 12 Loci Influencing Human Reproductive Behavior." Nature Genetics 48(12): 1462-72. DOI: 10.1038/ng.3698.

Barker, David J. P. 1997. “Maternal Nutrition, Fetal Nutrition, and Disease in Later Life." Nutrition 13(9): 807-13. DOI: 10.1016/s08999007(97)00193-7. . 1998. Mothers, Babies and Health in Later Life, 2nd ed. Edinburgh: Churchill Livingstone.

_ 2006. "Adult Consequences of Fetal Growth

Restriction." Clinical Obstetrics and Gynecology 49(2): 270-83. DOI: 10.1097/00003081200606000-00009.

Bengtsson, Tommy, and Göran Broström. 2009. “Do Conditions in Early Life Affect Old-Age Mortality Directly and Indirectly? Evidence from 19thCentury Rural Sweden." Social Science and Medicine 68(9): 1583-90. DOI: 10.1016/j.socscimed.2009.02.020.

Berenson, Gerald S., Wendy A. Wattigney, Weihang Bao, Sathanur R. Srinivasan, and Bhandaru Radhakrishnamurthy. 1995. Rationale to Study the Early Natural History of Heart Disease: The Bogalusa Heart Study. The American Journal of the Medical Sciences 310(S1): S22-28.

Bird, Adrian. 2002. "DNA Methylation Patterns and Epigenetic Memory." Genes and Development 16(1): 6-21. DOI: 10.1101/gad.947102.

Blackwell, Debra L., Mark D. Hayward, and Eileen M. Crimmins. 2001. "Does Childhood Health Affect Chronic Morbidity in Later Life?" Social Science and Medicine 52(8): 1269-84. DOI: 10.1016/ s0277-9536(00)00230-6.

Boardman, Jason D., Jonathan Daw, and Jeremy Freese. 2013. “Defining the Environment in Gene-Environment Research: Lessons from Social Epidemiology." American Journal of Public Health 103(S1): S64-72. DOI: 10.2105/ ajph.2013.301355.

Boardman, Jason D., Benjamin W. Domingue, and Jonathan Daw. 2015. "What Can Genes Tell Us About the Relationship Between Education and Health?" Social Science and Medicine 127 (February): 171-80. DOI: 10.1016/j.socscimed.2014.08.001.

Boardman, Jason D., Benjamin W. Domingue, and Jason M. Fletcher. 2012. "How Social and Genetic Factors Predict Friendship Networks." Proceedings of the National Academy of Sciences 109(43): 17377-81. DOI: 10.1073/pnas.1208975109. 
Boardman, Jason D., Michael E. Roettger, Benjamin W. Domingue, Matthew B. McQueen, Brett C. Haberstick, and Kathleen M. Harris. 2012. “GeneEnvironment Interactions Related to Body Mass: School Policies and Social Context as Environmental Moderators." Journal of Theoretical Politics 24(3): 370-388. DOI: 10.1177/0951629812 437751.

Boas, Franz. 1912. "Changes in the Bodily Form of Descendants of Immigrants." American Anthropologist 14(3): 530-62. DOI: 10.1525/aa.1912.14 .3.02a00080

Boyce, W. Thomas, and Michael S. Kobor. 2015. “Development and the Epigenome: The 'Synapse' of Gene-Environment Interplay." Developmental Science 18(1): 1-23.

Brody, Gene H., Tianyi Yu, Edith Chen, Gregory E. Miller, Steven M. Kogan, and Steven R. H. Beach. 2013. "Is Resilience Only Skin Deep? Rural African Americans' Socioeconomic Status-Related Risk and Competence in Preadolescence and Psychological Adjustment and Allostatic Load at Age 19." Psychological Science 24(7): 1285-93. DOI: 10.117/0956797612471954.

Cameron, Noe, and Ellen W. Demerath. 2002. “Critical Periods in Human Growth and Their Relationship to Diseases of Aging." American Journal of Physical Anthropology 119(S35): 159-84. DOI: 10.1002/ajpa.10183.

Case, Anne, Angela Fertig, and Christina Paxson. 2005. "The Lasting Impact of Childhood Health and Circumstance." Journal of Health Economics 24(2): 365-89. DOI: 10.1016/j.jhealeco.2004.09 .008 .

Case, Anne, Darren Lubotsky, and Christina Paxson. 2002. "Economic Status and Health in Childhood: The Origins of the Gradient." American Economic Review 92(5): 1308-34. DOI: 10.1257/000282802762024520.

Case, Anne, and Christina Paxson. 2010. "Causes and Consequences of Early-Life Health." Demography 47(Suppl 1): S65-85.

Caspi, Avshalom, Karen Sugden, Terrie E. Moffitt, Alan Taylor, et al. 2003. "Influence of Life Stress on Depression: Moderation by a Polymorphism in the 5-HTT Gene." Science 301(5631): 386-89. DOI: $10.1126 /$ science.1083968.

Cawley, John 2004. "The Impact of Obesity on Wages." The Journal of Human Resources 39(2): 451-74.

Charney, Evan, and William English. 2012. “Candi- date Genes and Political Behavior." American Political Science Review 106(1): 1-34. DOI: 10.1017 /s0003055411000554.

Christensen, Brock C., E. Andres Houseman, Carmen J. Marsit, Shichun Zheng, et al. 2009. "Aging and Environmental Exposures Alter TissueSpecific DNA Methylation Dependent upon CpG Island Context." PLoS Genetics 5(8): e1000602. DOI: 10.1371/journal.pgen.1000602.

Cohen, Sheldon, Denise Janicki-Deverts, Edith Chen, and Karen A. Matthews. 2010. "Childhood Socioeconomic Status and Adult Health." Annals of the New York Academy of Science 1186 (February): 37-55.

Cohen, Sheldon, Joseph E. Schwartz, Elissa Epel, Clemens Kirschbaum, Steve Sidney, and Teresa Seeman. 2006. "Socioeconomic Status, Race, and Diurnal Cortisol Decline in the Coronary Artery Risk Development in Young Adults (CARDIA) Study." Psychosomatic Medicine 68(1): 41-50. DOI: 10.1097/01.psy.0000195967.51768.ea.

Cole, Steven W. 2013. “Social Regulation of Human Gene Expression: Mechanisms and Implications for Public Health." American Journal of Public Health 103(S1): S84-S92. DOI: 10.2105/ajph .2012.301183.

—. 2014. "Human Social Genomics." PLoS Genetics 10(8): e1004601. DOI: 10.1371/journal.pgen 1004601.

Conley, Dalton 2016. "Socio-Genomic Research Using Genome-Wide Molecular Data." Annual Review of Sociology 42(1): 275-99. DOI: 10.1146/ annurev-soc-081715-074316.

Conley, Dalton, and Neil G. Bennett. 2000. "Is Biology Destiny? Birth Weight and Life Chances." American Sociological Review 65(3): 458-67. DOI: $10.2307 / 2657467$.

Crimmins, Eileen M., and Caleb E. Finch. 2006. “Infection, Inflammation, Height, and Longevity." Proceedings of the National Academy of Sciences 103(2): 498-503. DOI: 10.1073/pnas.0501470103.

Crimmins, Eileen M., Yuan Zhang, and Yasuhiko. Saito. 2016. "Trends over 4 Decades in DisabilityFree Life Expectancy in the United States." American Journal of Public Health 106(7): 128793. DOI: 10.2105/ajph.2016.303120.

Currie, J., and E. Moretti. 2007. “Biology as Destiny? Short- and Long-Run Determinants of Intergenerational Transmission of Birth Weight." Journal of Labor Economics 25(2): 231-64. DOI: 10.1086 /511377. 
Currie, Janet, and Mark Stabile. 2003. "Socioeconomic Status and Child Health: Why Is the Relationship Stronger for Older Children?" American Economic Review 93(5): 1813-23. DOI: 10.1257 /000282803322655563.

Daw, Jonathan, Michael Shanahan, Kathleen M. Harris, Andrew Smolen, Brett Haberstick, and Jason D. Boardman. 2013. “Genetic Sensitivity to Peer Behaviors: 5HTTLPR, Smoking, and Alcohol Consumption." Journal of Health and Social Behavior 54(1): 92-108. DOI: 10.1177/0022146512468591.

Dedeurwaerder, Sarah, Matthieu Defrance, Emilie Calonne, Hélène Denis, Christos Sotiriou, and François Fuks. 2011. “Evaluation of the Infinium Methylation 450K Technology." Epigenomics 3(6): 771-84. DOI: 10.2217/Epi.11.105.

DeSantis, Amy S., Emma K. Adam, Leah D. Doane, Susan Mineka, Richard E. Zinbarg, and Michelle G. Craske. 2007. “Racial/Ethnic Differences in Cortisol Diurnal Rhythms in a Community Sample of Adolescents." Journal of Adolescent Health 41(1): 3-13. DOI: 10.1016/j.jadohealth.2007.03.006.

Domingue, Benjamin W., David H. Rehkopf, Dalton Conley, and Jason D. Boardman. 2018. “Geographic Clustering of Polygenic Scores at Different Stages of the Life Course." RSF: The Russell Sage Foundation Journal of the Social Sciences 4(4): 137-49. DOI: 10.7758/RSF.2018.4.4.08.

Elo, Irma T., and Samuel H. Preston. 1992. "Effects of Early-Life Conditions on Adult Mortality: A Review." Population Index 58(2): 186-212. DOI: 10 $.2307 / 3644718$.

Engel, George L. 1978. “The Biopsychosocial Model and the Education of Health Professionals." Annals of the New York Academy of Sciences 310 (June): 169-87.

Essex, Marilyn J., W. Thomas Boyce, Clyde Hertzman, Lucia L. Lam, Jeffrey M. Armstrong, Sarah M. Neumann, and Michael S. Kobor. 2013. “Epigenetic Vestiges of Early Developmental Adversity: Childhood Stress Exposure and DNA Methylation in Adolescence." Child Development 84(1): 58-75. DOI: 10.1111/j.1467-8624.2011.01641.x.

Figlio, David, Jonathan Guryan, Krzysztof Karbownik, and Jeffrey Roth. 2014. "The Effects of Poor Neonatal Health on Children's Cognitive Development." American Economic Review 104(12): 39213955.

Fletcher, Jason M., and Michael R. Richards. 2012. “Diabetes's 'Health Shock' to Schooling and Earning: Increased Dropout Rates and Lower
Wages and Employment in Young Adults." Health Affairs 31(1): 27-34. DOI: 10.1377/hlthaff.2011 .0862

Freedman, Vicki A., and Brenda C. Spillman. 2014. “Disability and Care Needs Among Older Americans." Milbank Quarterly 92(3): 509-41. DOI: 10 .1111/1468-0009.12076.

Freese, Jeremy, and Sara Shostak. 2009. "Genetics and Social Inquiry." Annual Review of Sociology 35(1): 107-28. DOI: 10.1146/annurev-soc-070308 -120040 .

Fry, Rebecca C., Julia E. Rager, Haibo Zhou, Baiming Zou, June W. Brickey, Jenny Ting, Davids B.

Peden, and Neil E. Alexis. 2012. "Individuals with Increased Inflammatory Response to Ozone Demonstrate Muted Signaling of Immune Cell Trafficking Pathways." Respiratory Research 13(1): 89. DOI: 10.1186/1465-9921-13-89.

Furstenberg, Frank F. 2003. "Teenage Childbearing as a Public Issue and Private Concern." Annual Review of Sociology 29(1): 23-39. DOI: 10.1146/ annurev.soc.29.010202.100205.

George, Linda K. 2009. “Conceptualizing and Measuring Trajectories." In The Craft of Life Course Research, edited by Glenn H. Elder Jr. and Janet Z. Giele. New York: Guilford Press.

Glass, Christy, Steven Haas, and Eric N. Reither. 2010. “The Skinny on Success: Adolescent Body Mass, Gender and Occupational Attainment." Social Forces 88(4): 1777-806.

Glass, Thomas A., and Matthew J. McAtee. 2006. “Behavioral Science at the Crossroads in Public Health: Extending Horizons, Envisioning the Future." Social Science and Medicine 62(7): 165071. DOI: 10.1016/j.soescimed.2005.08.044.

Gluckman, Peter D., Mark A. Hanson, Cyrus Cooper, and Kent L. Thornburg. 2008. "Effect of In Utero and Early-Life Conditions on Adult Health and Disease." New England Journal of Medicine 359(1): 61-73. DOI: 10.1056/nejmra0708473.

Goosby, Bridget J., Jacob E. Cheadle, Whitney Strong-Bak, Taylor C. Roth, and Timothy D. Nelson. 2018. "Perceived Discrimination and Adolescent Sleep in a Community Sample." RSF: The Russell Sage Foundation Journal of the Social Sciences 4(4): 43-61. DOI: 10.7758/RSF.2018.4 .4 .03 .

Gottleib, Gilbert. 1991. “Experiential Canalization of Behavioral Development: Theory." Developmental Psychology 27(1): 4-13.

Gravlee, Clarence C. 2009. “How Race Becomes Bi- 
ology: Embodiment of Social Inequality." American Journal of Physical Anthropology 139(1): 4757. DOI: 10.1002/Ajpa.20983.

Grönniger, Elke, Barbara Weber, Oliver Heil, Nils Peters, Franz Stäb, Horst Wenck, Bernhard Korn, Marc Winnefeld, and Frank Lyko. 2010. “Aging and Chronic Sun Exposure Cause Distinct Epigenetic Changes in Human Skin." PLoS Genetics 6(5): e1000971. DOI: 10.1371/journal.pgen .1000971.

Gruenewald, Tara L., Margaret E. Kemeny, Najib Aziz, and John L. Fahey. 2004. "Acute Threat to the Social Self: Shame, Social Self-Esteem, and Cortisol Activity." Psychosomatic Medicine 66(6): 915-24.

Hahn, Rovert A. 1995. Sickness and Healing: An Anthropological Perspective. New Haven, Conn.: Yale University Press.

Halfon, Neal, and Miles Hochstein. 2002. “Life Course Health Development: An Integrated Framework for Developing Health, Policy, and Research." Milbank Q 80(3): 433-79.

Hallqvist, Johan, John Lynch, Mel Bartley, Thierry Lang, and David Blane. 2004. “Can We Disentangle Life Course Processes of Accumulation, Critical Period and Social Mobility? An Analysis of Disadvantaged Socio-economic Positions and Myocardial Infarction in the Stockholm Heart Epidemiology Program." Social Science and Medicine 58(8): 1555-62. DOI: 10.1016/s0277-9536 (03)00344-7.

Han, Euna, Edward C. Norton, and Sally C. Stearns. 2009. "Weight and Wages: Fat Versus Lean Paychecks." Health Economics 18(5): 535-48.

Harris, Kathleen M. 2010. "An Integrative Approach to Health." Demography 47(1): 1-22.

Harris, Kathleen M., and Hedwig Lee. 2011. “Social and Economic Consequences of Obesity During the Transition to Adulthood." Paper presented at the Annual Meetings of the Popualtion Association of America, Washington, D.C. (March 31April 2, 2011).

Hayward, Mark D., and Bridget K. Gorman. 2004. "The Long Arm of Childhood: The Influence of Early-Life Social Conditions on Men's Mortality." Demography 41(1): 87-107. DOI: 10.1353/dem .2004.0005.

Heijmans, Bastiaan. T., Elmar W. Tobi, Aryeh D. Stein, Hein Putter, Gerard J. Blauw, Ezra S. Susser, P. Eline Slagboom, and L. H. Lumey. 2008. "Persistent Epigenetic Differences Associ- ated with Prenatal Exposure to Famine in $\mathrm{Hu}$ mans." Proceedings of the National Academy of Sciences 105(44): 17046-49. DOI: 10.1073/ pnas.0806560105.

Hertzman, Clyde. 2012. “Putting the Concept of Biological Embedding in Historical Perspective." Proceedings of the National Academy of Sciences 109(Supplement 2): 17160-67.

Hertzman, Clyde, and Tom Boyce. 2010. “How Experience Gets Under the Skin to Create Gradients in Developmental Health." Annual Review of Public Health 31: 329-47. DOI: 10.1146/annurev.publhealth.012809.103538.

House, James S., Karl R. Landis, and Debra Umberson. 1988. "Social Relations and Health." Science 241(4865): 540-45.

Hubert, H. B., E. D. Eaker, R. J. Garrison, and William P. Castelli. 1987. “Life-Style Correlates of Risk Factor Change in Young Adults: An Eight-Year Study of Coronary Heart Disease Risk Factors in the Framingham Offspring." American Journal of Epidemiology 125(5): 812-31. DOI: 10.1093/oxfordjournals.aje.a114598.

Hutter, Carolyn M., Leah E. Mechanic, Nilanjan Chatterjee, Peter Kraft, et al. 2013. “Gene-

Environment Interactions in Cancer Epidemiology: A National Cancer Institute Think Tank Report." Genetic Epidemiology 37(7): 643-57. DOI: 10.1002/gepi.21756.

International Human Epigenome Consortium (IHEC). 2013. "Goals, Structure, Policies and Guidelines." Cambridge: IHEC.

Jablonka, Eva, and Marion J. Lamb. 2002. “The Changing Concept of Epigenetics." From Epigenesis to Epigenetics: The Genome in Context 981 (December): 82-96.

—. 2015. "The Inheritance of Acquired Epigenetic Variations." International Journal of Epidemiology 44(4): 1094-103. DOI: 10.1093/ije/dyv020.

Jackson, Margot I., and Susan E. Short. 2018. “Gender Differences in Biological Function in Young Adulthood: An Intragenerational Perspective." RSF: The Russell Sage Foundation Journal of the Social Sciences 4(4): 98-119. DOI: 10.7758/ RSF.2018.4.4.06.

Kleinman, Arthur. 1986. Social Origins of Distress and Disease. New Haven, Conn.: Yale University Press.

Krieger, Nancy 2005. “Embodiment: A Conceptual Glossary for Epidemiology." J Epidemiol Community Health 59(5): 350-55. DOI: 10.1136/jech .2004 .024562 . 
Kuh, Diana, and Yoav Ben-Shlomo. 2004. "A Life Course Approach to Chronic Disease Epidemiology." In A Life Course Approach to Chronic Disease Epidemiology, 2nd ed., ed. Yoav BenShlomo. Oxford: Oxford University Press.

Langevin, Scott M., E. Andresa Houseman, Brock C. Christensen, John K. Wiencke, Heather H. Nelson, Margaret R. Karagas, Carmen J. Marsit, and Karl T. Kelsey. 2011. “The Influence of Aging, Environmental Exposures and Local Sequence Features on the Variation of DNA Methylation in Blood." Epigenetics 6(7): 908-19. DOI: 10.4161/ epi.6.7.16431.

Lasker, Gabriel W. 1969. “Human Biological Adaptability: The Ecological Approach in Physical Anthropology." Science 166(3912): 1480-86.

Lewontin, Richard C., and Richard Levins. 2007. Biology Under the Influence: Dialectical Essays on Ecology, Agriculture, and Health. New York: Monthly Review Press.

Li, Shengxu, Wei Chen, Sathanur R. Srinivasan, and Gerald S Berenson. 2004. “Childhood Blood Pressure as a Predictor of Arterial Stiffness in Young Adults." Hypertension 43(3): 541-46.

Lindau, Stacy T., and Thomas W. McDade. 2007. “Minimally Invasive and Innovative Methods for Biomeasure Collection in Population-Based Research." In Biosocial Surveys, edited by Maxine Weinstein, James W. Vaupel, and Kenneth W. Wachter. Washington, D.C.: National Academies Press.

Link, Bruce G., and Jo Phelan. 1995. “Social Conditions as Fundamental Causes of Disease." Journal of Health and Social Behavior, Extra Issue: Forty Years of Medical Sociology: The State of the Art and Directions for the Future: 80-94.

Ludwig, Jens, Lisa Sanbonmatsu, Lisa Gennetian, Emma Adam, Greg J. Duncan, Lawrence F. Katz, and Thomas W. McDade. 2011. "Neighborhoods, Obesity, and Diabetes-A Randomized Social Experiment." New England Journal of Medicine 365(16): 1509-19.

Marino, Miguel, Yi Li, Michael N. Rueschman, John Winkelman, J. M. Ellenbogen, Jo M. Solet, Hilary Dulin, Lisa F. Berkman, and Orfeu M. Buxton. 2013. “Measuring Sleep: Accuracy, Sensitivity, and Specificity of Wrist Actigraphy Compared to Polysomnography." Sleep 36(11): 1747-55.

Marmot, Michael, Martin Shipley, Eric Brunner, and Harry Hemingway. 2001. “Relative Contribution of Early Life and Adult Socioeconomic Factors to
Adult Morbidity in the Whitehall II Study." Journal of Epidemiology and Community Health 55(5): 301-07.

Marmot, Michael, and Richard G. Wilkinson. 2005. Social Determinants of Health, 2nd ed. Oxford: Oxford University Press.

Massey, Douglas S., Brandon Wagner, Louis Donnelly, Sara McLanahan, Jeanne Brooks-Gunn, Irwin Garfinkel, Colter Mitchell, and Daniel A. Notterman. 2018. “Neighborhood Disadvantage and Telomere Length: Results from the Fragile Families Study." RSF: The Russell Sage Foundation Journal of the Social Sciences 4(4): 28-42. DOI: 10.7758/RSF.2018.4.4.02.

McClure, Elizabeth, Lydia Feinstein, Sara FerrandoMartínez, Manuel Leal, Sandro Galea, and Allison E. Aiello. 2018. "The Great Recession and Immune Function." RSF: The Russell Sage Foundation Journal of the Social Sciences 4(4): 62-81. DOI: 10.7758/RSF.2018.4.4.04.

McDade, Thomas W., Kharah M. Ross, Ruby L. Fried, Jesusa M. Arevalo, Jeffrey Ma, Gregory E. Miller, and Steve W. Cole. 2016. "Genome-Wide Profiling of RNA from Dried Blood Spots: Convergence with Bioinformatic Results Derived from Whole Venous Blood and Peripheral Blood Mononuclear Cells." Biodemography and Social Biology 62(2): 182-97. DOI: 10.1080/19485565 .2016.1185600.

McDade, Thomas W., Calen Ryan, Meaghan Jones, Julia L. Maclsaac, Alexander M. Morin, Jess M. Meyer, Judith B. Borja, Gregory E. Miller, Michael S. Kobor, and Christopher W. Kuzawa. 2017. "Social and Physical Environments Early in Development Predict DNA Methylation of Inflammatory Genes in Young Adulthood." Proceedings of the National Academy of Sciences 114(29): 7611-16.

McDade, Thomas W., Sharon Williams, and J. Josh Snodgrass. 2007. “What a Drop Can Do: Dried Blood Spots as a Minimally Invasive Method for Integrating Biomarkers into Population-Based Research." Demography 44(4): 899-925.

McEwen, Bruce S. 1998. "Stress, Adaptation and Disease: Allostasis and Allostatic Load." Annals of the New York Academy of Sciences 840 (May): 33-44.

McEwen, Bruce S., and Elizabeth N. Lasley. 2002. The End of Stress as We Know It. New York: Dana Press.

Miller, Gregory E., Edith Chen, Alexandra K. Fok, Hope Walker, Alvin Lim, Erin F. Nicholls, and Mi- 
chael S. Kobor. 2009. “Low Early-Life Social Class Leaves a Biological Residue Manifested by Decreased Glucocorticoid and Increased Proinflammatory Signaling." Proceedings of the National Academy of Sciences 106(34): 14716-21. DOI: 10.1073/pnas.0902971106.

Miller, Gregory E., Tianyi Yu, Edith Chen, and Gene H. Brody. 2015. “Self-Control Forecasts Better Psychosocial Outcomes but Faster Epigenetic Aging in Low-SES Youth." Proceedings of the National Academy of Sciences 112(33): 10325-30.

Mills, Melinda C., Nicola Barban, and Felix C. Tropf. 2018. "The Sociogenomics of Polygenic Scores of Reproductive Behavior and Their Relationship to Other Fertility Traits." RSF: The Russell Sage Foundation Journal of the Social Sciences 4(4): 122-36. DOI: 10.7758/RSF.2018.4.4.07.

Murphy, Michael L. M., George M. Slavich, Nicolas Rohleder, and Gregory E. Miller. 2012. “Targeted Rejection Triggers Differential Pro- and Antiinflammatory Gene Expression in Adolescents as a Function of Social Status." Clinical Psychological Science 1(1): 30-40. DOI: $10.1177 / 2167702612455743$.

National Center for Health Statistics. 2016. Health, United States. 2015: With Special Feature on Racial and Ethnic Health Disparities. Hyattsville, Md.: U.S. Department of Health and Human Services.

Needham, Belinda L., Jennifer A. Smith, Wei Zhao, Xu Wang, Bhramar Mukherjee, Sharon L. Kardia, Teresa E. Seeman, Yongmei Liu, and Ava V. Diez Roux. 2015. “Life Course Socioeconomic Status and DNA Methylation in Genes Related to Stress Reactivity and Inflammation: The Multi-ethnic Study of Atherosclerosis." Epigenetics 10(10): 958-69. DOI: 10.1080/15592294.2015.1085139.

Nguyen, Quynh C., Joyce W. Tabor, Pamela P. Entzel, Yan Lau, Chirayath Suchindran, Jon M. Hussey, Carolyn T. Halpern, Kathleen M. Harris, and Eric A. Whitsel. 2011. "Discordance in National Estimates of Hypertension Among Young Adults." Epidemiology 22(4): 532-41. DOI: 10.1097/ede $.0 b 013 e 31821 c 79 d 2$.

North, Kari E., and Lisa J. Martin. 2008. “The Importance of Gene-Environment Interaction: Implications for Social Scientists." Sociological Methods and Research 37(2): 164-200. DOI: 10.1177 /0049124108323538.

Okbay, Aysu, Jonathan P. Beauchamp, Mark A. Fontana, James J. Lee, et al. 2016. “Genome-Wide
Association Study Identifies 74 Loci Associated with Educational Attainment." Nature 533(7604): 539-42.

Palloni, Alberto. 2006. “Reproducing Inequalities: Luck, Wallets, and the Enduring Effects of Childhood Health." Demography 43(4): 587-615. DOI: 10.1353/dem.2006.0036.

Pearlin, Leonard I. 1989. "The Sociological Study of Stress." Journal of Health and Social Behavior 30(3): 241. DOI: 10.2307/2136956.

Phillips, David I., Brian R. Walker, Rebecca M. Reynolds, Daniel E. Flanagan, Peter J. Wood, Clive Osmond, and Christopher B. Whorwood. 2000. “Low Birth Weight Predicts Elevated Plasma Cortisol Concentrations in Adults from 3 Populations." Hypertension 35(6): 1301-306.

Powell, Brian, Laura Hamilton, Bianca Manago, and Simon Cheng. 2016. "Implications of Changing Family Forms for Children." Annual Review of Sociology 42(1): 301-22. DOI: 10.1146/annurev-soc $-081715-074444$.

Preston, Samuel H., Mark E. Hill, and Greg L. Drevenstedt. 1998. “Childhood Conditions that Predict Survival to Advanced Ages Among African-Americans." Social Science and Medicine 47(9): 1231-46. DOI: 10.1016/s0277-9536(98)001 80-4.

Pudrovska, Tetyana, and Benedicta Anikputa. 2014. “Early-Life Socioeconomic Status and Mortality in Later Life: An Integration of Four Life-Course Mechanisms." Journals of Gerontology Series B: Psychological Sciences and Social Sciences 69(3): 451-60.

Qu, Yang, Adriana Galván, Andrew J. Fuligni, and Eva H. Telzer. 2018. “A Biopsychosocial Approach to Examine Mexican American Adolescents' Academic Achievement and Substance Use." RSF: The Russell Sage Foundation Journal of the Social Sciences 4(4): 84-97. DOI: 10.7758/RSF.2018 .4.4.05.

Rietveld, Cornelius, Sarah Medland, Jaime Derringer, Jian Yang, et al. 2013. “GWAS of 126,559 Individuals Identifies Genetic Variants Associated with Educational Attainment." Science 340(6139): 1467-71.

Rowe, David C., Kristen C. Jacobson, and Edwin J. Van den Oord. 1999. "Genetic and Environmental Influences on Vocabulary IQ: Parental Education Level as Moderator." Child Development 70(5): 1151-62. DOI: 10.1111/1467-8624.00084.

Scheper-Hughes, Nancy, and Margaret M. Lock. 
1987. “The Mindful Body: A Prolegomenon to Future Work in Medical Anthropology." Medical Anthropology Quarterly 1(1): 6-41.

Schmitz, Lauren, and Dalton Conley. 2016. “The Long-Term Consequences of Vietnam-Era Conscription and Genotype on Smoking Behavior and Health." Behavior Genetics 46(1): 43-58. DOI: 10.1007/s10519-015-9739-1.

_. 2017. "Modeling Gene-Environment Interactions with Quasi-Natural Experiments." Journal of Personality 85(1): 10-21. DOI: 10.1111/jopy.12227. Seeman, Teresa E., Bruce S. McEwen, John W. Rowe, and Burton H. Singer. 2001. "Allostatic Load as a Marker of Cumulative Biological Risk: MacArthur Studies of Successful Aging." Proceedings of the National Academy of Sciences 98(8): 4770-75.

Seligman, Rebecca 2014. Possessing Spirits and Healing Selves: Embodiment and Transformation in an Afro-Brazilian Religion. New York: Palgrave Macmillan.

Shanahan, Michael J., and Jason D. Boardman. 2009. "Genetics and Behavior in the Life Course: A Promising Frontier." In The Craft of Life Course Research, edited by Glenn H. Elder Jr., and Janet Z. Giele. New York: Guilford Press.

Shanahan, Michael J., Scott M. Hofer, and Lilly Shanahan. 2003. "Biological Models of Behavior and the Life Course." In Handbook of Sociology and Social Research, edited by Jeylan T. Mortimer and Michael J. Shanahan. New York: Springer Science.

Sisk, Cheryl L., and Julia L. Zehr. 2005. “Pubertal Hormones Organize the Adolescent Brain and Behavior." Frontiers in Neuroendocrinology 26(34): 163-74. DOI: 10.1016/j.yfrne.2005.10.003.

Slavich, George M., and Steven W. Cole. 2013. "The Emerging Field of Human Social Genomics." Clinical Psychological Science 1(3): 331-348. DOI: 10.1177/2167702613478594.

Smith, Caitlin J., and Kelli K. Ryckman. 2015. “Epigenetic and Developmental Influences on the Risk of Obesity, Diabetes, and Metabolic Syndrome." Diabetes, Metabolic Syndrome and Obesity: Targets and Therapy 8 (June): 295-302. DOI: 10.2147/DMSO.S61296.

Smith, James P. 2009. “Reconstructing Childhood Health Histories." Demography 46(2): 387-403. DOI: 10.1353/dem.0.0058.

Sterling, Peter, and Joseph Ayer. 1988. "Allostasis: A New Paradigm to Explain Arousal Pathology." In Handbook of Life Stress, Cognition and Health, edited by Shirley Fischer and James Reason. New York: John Wiley \& Sons.

Stinson, Sara, Barry Bogin, and Dennis O'Rourke. 2012. Human Biology: An Evolutionary and Biocultural Perspective. New York: Wiley-Blackwell.

Sweeney, Megan M., and R. Kelly Raley. 2014. "Race, Ethnicity, and the Changing Context of Childbearing in the United States." Annual Review of Sociology 40(1): 539-58. DOI: 10.1146/annurevsoc-071913-043342.

Thayer, Zaneta M., and Christopher W. Kuzawa. 2011. "Biological Memories of Past Environments: Epigenetic Pathways to Health Disparities." Epigenetics 6(7): 798-803.

Tobi, Elmar W., L. H. Lumey, Rudolf P. Talens, Dennis Kremer, Hein Putter, Aryeh D. Stein, P. Eline Slagboom, and Bastiaan T. Heijmans. 2009. “DNA Methylation Differences After Exposure to Prenatal Famine Are Common and Timing- and SexSpecific." Human Molecular Genetics 18(21): 4046-53. DOI: 10.1093/hmg/ddp353.

Uchino, Bert, John T. Cacioppo, and Janice K. Kiecolt-Glaser. 1996. “The Relationship Between Social Support and Physiological Processes: A Review with Emphasis on Underlying Mechanisms and Implications for Health." Psychological Bulletin 119(3): 488-531.

Wadhwa, Pathik. D., Claudia Buss, Sonja Entringer, and James M. Swanson. 2009. “Developmental Origins of Health and Disease: Brief History of the Approach and Current Focus on Epigenetic Mechanisms." Seminars in Reproductive Medicine 27(5): 358-68. PubMed: 19711246.

Waite, Linda, and Aniruddha Das. 2010. “Families, Social Life, and Well-Being at Older Ages." Demography 47 Suppl: S87-109. PMID:21302422.

Ward, Brian W., Jeannine S. Schiller, and Richard A. Goodman. 2014. “Multiple Chronic Conditions Among U.S. Adults: A 2012 Update." Preventing Chronic Disease 11. DOI: 10.5888/pcd11.130389.

Weinstein, Maxine, James W. Vaupel, and Kenneth W. Wachter, eds. 2007. Biosocial Surveys. Washington, D.C.: National Academies Press.

Wilcox, W. Bradford, and Robert I. Lerman. 2014. "For Richer, for Poorer: How Family Structures Economic Success in America." Washington, D.C.: American Enterprise Institute.

Wolfe, Barbara, William N. Evans, and Teresa E. Seeman. 2012. The Biological Consequences of Socioeconomic Inequalities. New York: Russell Sage Foundation. 
Yang, Yang Claire, Courtnay Boen, Karen Gerken,

Ting Li, Kristen Schorpp, and Kathleen M. Harris. 2016. “Social Relationships and Physiological Determinants of Longevity Across the Human Life Span." Proceedings of the National Academy of Sciences 113(3): 578-83. DOI: 10.1073/pnas .1511085112 .

Yang, Yang Claire, Karen Gerken, Kristen Schorpp, Courtnay Boen, and Kathleen M. Harris. 2017. “Early Life Socioeconomic Status and Adult
Physiological Functioning: A Life Course Examination of Biosocial Mechanisms." Biodemography and Social Biology 63(2): 87-103. Yang, Yang Claire, Kristen Schorpp, and Kathleen M. Harris. 2014. “Social Support, Social Strain and Inflammation: Evidence from a National Longitudinal Study of U.S. Adults." Social Science and Medicine 107 (April): 124-35. DOI: 10.1016/j.socscimed.2014 .02 .013 . 